NOTAS Y COMENTARIOS

\title{
DESCUBRIMIENTO Y MODELADO: LA MACROECONOMÍA DE LAS ECONOMÍAS ABIERTAS Y OTROS CASOS ${ }^{\wedge}$
}

\author{
IDENTIFICATION AND MODELING: THE MACROECONOMICS \\ OF OPEN ECONOMIES AND OTHER CASES
}

Juan Carlos de Pablo*o

enviado: 23 abril 2021 - aceptado: 30 abril 2021

\section{Resumen}

La literatura especializada asocia la macroeconomía de corto plazo de economías abiertas con Robert Alexander Mundell y Rudiger Wilhelm Dornbusch. Sin embargo, ¿fueron ellos los primeros que se ocuparon de la cuestión? Si no lo fueron, ¿cuál fue su aporte? En este artículo se responden estas preguntas, al mismo tiempo que se abordan otros casos dentro del análisis económico.

Palabras clave: macroeconomía, corto plazo, economía abierta.

Códigos JEL: B22, B31, E00.

\begin{abstract}
The specialized literature associates the short-term macroeconomics of open economies with Robert Alexander Mundell and Rudiger Wilhelm Dornbusch.

\footnotetext{
de Pablo, J. C. (2022). Descubrimiento y modelado: la macroeconomía de las economías abiertas y otros casos. Estudios económicos, 39(78), pp. 243-253. DOI: https://doi.org/10.52292/j.estudecon.2022.2652 titular de la Academia Nacional de Ciencias Económicas, Argentina. Correo electrónico: depablo43@hotmail.com preliminar.
}

* Titular de DEPABlOCONSUlt, Universidad del CEMA, Universidad de San Andrés, Miembro

- Agradezco a Guillermo Antonio Roberto Calvo los comentarios que me hizo llegar a la versión
\end{abstract}


However, were they the first who addressed this issue? If not, what was their contribution? This article answers these questions at the same time that other cases are studied within the economic analysis.

Keywords: macroeconomics, short term, open economy.

Código JEL: B22, B31, E00. 


\section{EL CASO DE LA MACRO DE CORTO PLAZO}

Entre 1957 y 1963 Mundell publicó un conjunto de trabajos, recogidos en Mundell (1968), referidos a la macroeconomía de corto plazo. Dichos trabajos impactaron, tanto por su contenido como por la nitidez de su texto y los gráficos utilizados. Dornbusch (1980), por su parte, sistematizó el referido campo de estudio.

No les quito mérito a ninguno de los dos autores, pero me parece importante precisar en qué consistió dicho mérito. Para lo cual es preciso prestarle atención a la labor desarrollada en la denominada Sección Económica (SE), una oficina del gobierno inglés creada en 1939. Dicha oficina constituyó "el primer grupo de economistas profesionales que trabajó con dedicación exclusiva como asesores gubernamentales en Inglaterra, y muy probablemente en cualquier país. No tenía el monopolio del asesoramiento, pero ocupaba un lugar central y sus puntos de vista eran muy tenidos en cuenta" (Cairncross \& Watts, 1989).

Laboraron en la referida oficina, entre otros y por orden alfabético, Alexander Kirkland Cairncross, John Marcus Fleming, Robert Lowe Hall, Ian Malcom David Little, James Edward Meade, Lionel Charles Robbins, George Lennox Sharman Shackle, John Richard Nicholas Stone y Trevor Winchester Swan. Meade y Stone recibieron el premio Nobel en economía, en 1977 y 1984, respectivamente.

El texto completo de Cairncross y Watts, así como el capítulo 12 de la monumental biografía de Robbins, escrita por Howson (2011), dedicado al período en el cual la SE fue dirigida por Robbins, documentan de manera muy instructiva tanto la sustancia como las condiciones en las cuales los referidos economistas analizaron el entonces presente y el probable futuro (léase, posterior a la Segunda Guerra Mundial) de la economía inglesa. En buena parte de los "memos" redactados, a la luz de las obvias restricciones externas que entonces enfrentaba Inglaterra, está el germen de la macroeconomía de economías abiertas.

La teoría general, que John Maynard Keynes publicó en 1936, planteó el funcionamiento de una economía cerrada. No porque en aquel entonces la economía inglesa lo fuera, sino porque ipodía funcionar como si lo fuese! En efecto, si como consecuencia del aumento de su nivel actividad económica, se incrementaban las importaciones desde Argentina, y se generaba un déficit comercial, esto básicamente aumentaba el saldo acreedor de la cuenta que el Estado argentino tenía en el Banco de Inglaterra. Esto dejó de ser así a partir de la Segunda Guerra Mundial, por ejemplo, con respecto a Estados Unidos. Digresión. Durante la guerra, los problemas externos no se circunscribieron a poder financiar el déficit comercial, 
porque también los abastecimientos, la capacidad de transporte internacional, etc., planteaban desafíos concretos.

¿Cuál es el mérito de Mundell y de Dornbusch, entonces? Modelar, para poder analizar mejor las implicancias de los hechos bajo análisis. No es poco, pero tampoco nos vayamos al otro extremo. Pero antes de desarrollar mi punto de manera general, corresponde citar otros casos que vienen a cuento.

\section{EL CASO DE LA TEORÍA CUANTITATIVA DEL DINERO}

Otra vez, la literatura especializada asocia el origen de la teoría cuantitativa del dinero, con Simon Newcomb e Irving Fisher ${ }^{1}$. ¿Fueron ellos los primeros que se ocuparon de la cuestión? Si no lo fueron, ¿cuál fue su aporte?

Sobre el particular, Oreste Popescu (1986a) es contundente: "un análisis detallado de los escritos producidos por las Cortes de Chuquisaca, permiten afirmar que la doctrina cuantitativa del dinero nació el 7 de septiembre de 1561". Sobre el particular, Popescu (1983, 1984 y 1986) destaca a Juan de Matienzo y a Tomás de Mercado, quienes no eran académicos, como en el caso de la SE, sino funcionario y sacerdote, respectivamente, pero agudos observadores y analistas.

En sus palabras:

"las reflexiones cuantitativistas formuladas por Juan de Matienzo (1520-1579), español, Oidor en la Audiencia de Charcas, en sus escritos de 1567 y (póstumo) de 1580, están entretejidas con elementos probatorios americanos. Sus reiteradas alusiones a la 'inspiración indiana' y a 'los que tienen la curiosidad de entender las cosas de esta tierra' no deja dudas en cuanto al engarce americano de su doctrina monetaria. Esta impresión, reforzada por la coincidencia de las observaciones de igual naturaleza recogidas en 1569 en los escritos de fray Tomás de Mercado, incita a la formulación de la hipótesis de trabajo del origen americano de la teoría cuantitativa del dinero... Si Mercado fundó la escuela de economía de la escolástica tardía en México, a Matienzo le corresponde el mérito de haber cristalizado la escuela de Chuquisaca en la América Hispana".

El 1 de febrero de 1562 las autoridades de la Audiencia de Charcas, al comenzar sus actividades en Chuquisaca, le enviaron una 'Carta a su Católica Real Majestad',

1 Por ejemplo, en la minuciosa reseña publicada por Milton Friedman (1987). Se citan anteriores antecedentes, pero no el que voy a mencionar a continuación. 
donde se enuncia la esencia de su doctrina cuantitativa. En esta Carta se pone de manifiesto lo que a cualquier conocedor de la provincia de los Charcas no se le podía pasar inadvertido, a saber, el fuerte desnivel de precios entre Lima y Potosí: 'en Potosí valen las cosas 4 veces más que en Lima ordinariamente'. Se reconoce la influencia de los factores de economía espacial: la distancia; pero al mismo tiempo se subraya la decisiva influencia del factor cuantitativo, 'a donde hay más dinero siempre las cosas valen más caras'... Si los integrantes de la Audiencia de Charcas podían dar por evidente su tesis cuantitativista en un ambiente como el de Chuquisaca y Potosí, no se hacían grandes ilusiones en cuanto a la receptividad de su doctrina en el mundo metropolitano... En la carta no aparece la firma de Juan de Matienzo, aunque es probable que haya participado en su redacción.

A su vez, Tomás de Mercado (ca.1525-1575) fue el más brillante representante de la teoría monetaria, y el más festejado por la crítica especializada. En sus palabras:

es de advertir no ser lo mismo el valor y el precio del dinero y su estima [esto último, el poder adquisitivo]. Ejemplo clarísimo: en las Indias vale el dinero lo mismo que acá, y lo mismo que en España; pero la estima es muy diferente en ambas partes. En mucho menos se estima en Indias que en España. Tras las Indias, donde en menos se tiene es en Sevilla, como ciudad que recibe en sí todo lo bueno que hay allá. Lo cual estima y apreciación se causa lo primero de tener gran abundancia o penuria de estos metales y como en aquellas partes (de las Indias) nace y se coge, tiéntese en poco.

\section{OTROS CASOS}

También vienen a cuento un interesante antecedente del enfoque monetario de la balanza de pagos, y el denominado efecto Olivera-Tanzi.

\section{Enfoque monetario de la balanza de pagos}

Federico Pinedo, en 1962, afirmó lo siguiente:

hay fases de la economía en que sin una política crediticia extremadamente dura no se puede mantener una moneda. Por consiguiente, no hay más remedio que persistir en esa política de dureza, aunque ello sea doloroso. Estamos en uno de ellos, en que toda la expansión crediticia deprime el valor de la moneda, y si se trata de una moneda como el peso, de libre convertibilidad, expele las divisas (Pinedo, 1968). 
El planteo constituye una nítida descripción de lo que la literatura especializada denomina el enfoque monetario de la balanza de pagos, cuyas monografías pioneras fueron publicadas por Frenkel y Johnson (1976), en base a una idea inicialmente planteada por David Hume. Digresión. Pinedo era totalmente consciente de la "iliquidez" que existió en Argentina antes y durante su gestión, pero - particularmente a partir de abril de 1962 - leyó correctamente que los argentinos disminuimos la demanda de dinero local, y por consiguiente toda política de reposición de pesos para combatir la iliquidez, lo único que iba a producir era pérdida de reservas y, eventualmente, devaluación (lo cual muestra que las acusaciones que le hicieron de llevar adelante una política monetaria restrictiva, como decisión autónoma de política económica, resultaban de diagnosticar incorrectamente lo que estaba ocurriendo con la demanda de dinero local).

\section{Efecto Olivera-Tanzi}

Durante el primer semestre de 1959 el nivel general de los precios se duplicó; y en aquel entonces el monto que tenía que pagar cada contribuyente, por ejemplo, por impuesto a las ganancias, no se ajustaba en función de la tasa de inflación, entre el momento en que se devengaba y aquel en el cual efectivamente se abonaba. El secretario de Hacienda de la Nación no necesitó conocer lo que posteriormente escribieron Julio Hipólito Guillermo Olivera y Vito Tanzi, para saber que "tenía un problema".

Este es otro caso en el cual la importancia de los trabajos publicados en 1967 y 1977, respectivamente, reside en extraer las implicancias del referido hecho. Cuestionando la tradicional relación causal, de déficit fiscal a inflación, en presencia del referido desfasaje. Hecho que se tuvo en cuenta cuando, a mediados de 1985, se calculó el tamaño de déficit fiscal que quedaría cuando la tasa de inflación pasara de $1 \%$ por día, a cero. Digresión. Hoy probablemente el efecto Olivera-Tanzi opere al revés, porque vía anticipos y retenciones, los contribuyentes abonan los impuestos casi simultáneamente con el momento en que se devengan, mientras que — por ejemplo, las jubilaciones - caen en términos reales cuando aumenta la tasa de inflación.

\section{ASIGNANDO MÉRITOS}

Hay mérito en Mundell y en Dornbusch, como hay mérito en Newcomb y Fisher, como lo hay en Frenkel, Johnson, Olivera y Tanzi. Porque modelar, entendiendo por tal extraer las implicancias de los descubrimientos, es una tarea valiosa 
y no siempre fácil2. Pero también hay mérito en quienes trabajaron en la SE, en Matienzo, Mercado y Pinedo; porque observar con "ojo clínico", sobre todo para identificar hechos que pueden significar cambios, tampoco es una tarea sencilla.

¿Por qué Paul Anthony Samuelson y Paul Robin Krugman, merecieron el premio Nobel en economía, en 1970 y 2008, respectivamente? Por modelar. Protección y salarios reales, la famosa monografía que escribió en colaboración con Wolfgang Friedrich Stolper, se basó en un trabajo escrito por Marion Crawford (1939), primera esposa de Samuelson, quien analizó lo que había ocurrido en Australia, precisamente, con las remuneraciones laborales, como consecuencia de la protección. Y la "nueva economía internacional" de Krugman está basada en las observaciones empíricas realizadas por Hans Martin Staffan Burestan Linder y Bela Balassa.

La naturaleza complementaria de los méritos observacionales y de modelado tiene que ser reconocida por la profesión. ¿Lo es? Huummm... Ejemplo: a quién valora más la profesión, ¿a Simón Smith Kuznets o a Robert Merton Solow?

Probable explicación, no justificación. Más de un lector de la versión preliminar de estas líneas me indicó que los pioneros suelen reconocer sus deudas intelectuales, mientras que los discípulos se circunscriben al análisis planteado por sus maestros y prefieren "no duplicar" la reseña de los antecedentes. Puede ser, pero como digo esto puede ser una explicación, no una justificación. La implicancia es que hay que inducir a los alumnos a que lean los originales, no solamente las versiones estilizadas, para evitar cometer el denominado "pecado o vicio ricardiano".

\section{CALVO, UNO QUE PATEA CON LAS DOS PIERNAS}

¿Se imagina a Albert Otto Hirschman modelando; se imagina a Gerard Debreu caminando por la calle y observando? Ambos son meritorios, cada uno en lo suyo.

Guillermo Calvo pertenece a la minoría de economistas que, en términos futbolísticos, patea con las dos piernas. Porque modeló (inconsistencia temporal, reformas no creíbles, etc.), pero en algunos casos descubrió y modeló. Por ejemplo, en el de los frenazos.

2 El "Malambo" de Alberto Ginastera, que forma parte del ballet Estancia, es una magnífica pieza musical que transcribe el malambo al idioma de la música clásica. Ginastera no inventó el malambo; su mérito consistió en haberlo "modelado". 
En sus palabras (Calvo, 2006):

trabajando en el FMI, luego de que yo me pegara una vuelta por América Latina, y viera que todos los países estaban teniendo apreciación del tipo real de cambio, acumulación de reservas, etc., me dije: 'esto no puede ser. Aquí hay algo que está haciendo mover esto, más allá de las políticas económicas de los países. ¿Qué tal si fuera la política monetaria de Estados Unidos?'. Porque si esto fuera así, el día que dicha política cambiara, todos se irían de narices. Todo el mundo decía que todo iba bien, en Argentina con el plan de Convertibilidad, y en cada país escuchabas la misma historia. Volví a Washington y con ayuda de Carmen Reinhart y Leonardo Leiderman (ellos hicieron la econometría), mostramos que claramente había factores externos. Escribimos un trabajo, titulado 'Influjo de capitales y apreciación del tipo real de cambio en América Latina: el rol de los factores externos', que fue publicado en 1993. La tesis central es 'está bien que los países hagan reformas, pero de golpe cambian las condiciones externas y todos se van de narices'.

El modelado vino después (Calvo, 1998).

Eso fue contra la cultura del Fondo, de una manera que inicialmente yo no me di cuenta. Porque el Fondo decía que, si uno hacía las cosas bien, no habría más problemas. Y yo decía: no sé, porque de pronto puede haber problemas. Esto generó una pelea muy fuerte dentro de la institución. Dejaron de mirarme con buenos ojos. 'Este académico se está metiendo y nos está queriendo cambiar la cultura', decían o, al menos, implicaban. Junto a lo cual, con Pablo Guidotti y Manmohan Kumar, trabajamos sobre la estructura de los bonos públicos, pensando que eso podría ser otra complicación, y lo fue. Fueron 2 cosas que al final el Fondo absorbió, pero no fue fácil.

En la academia se aprecia la originalidad, en las instituciones donde se formulan las políticas se aprecia el consenso. Si vos estás en el Fondo, y vas a negociar con un país, no podés llevar contigo todas las voces que normalmente tenemos los economistas. Tenés que alinearte. Eso crea una mentalidad. Si te alineaste durante 25 años de tu vida profesional, ya sos otro tipo. El trabajo hace al hombre. Viene un miembro de la academia, que anda tirando tiros para todos lados, pifiándola a veces; eso resulta ser una personalidad molesta. Y no parece seria, además, porque con frecuencia cambia de opinión. Esas dos culturas son difíciles de alinear, y no se han alineado. 


\section{PARECIDO, PERO DIFERENTE}

Una cuestión que se parece, pero que no es igual, es conocida como la "ley de eponimia de Stigler".

Merton (1973) planteó la ciencia como una empresa social. La principal implicancia de su análisis es que 'todos los descubrimientos científicos son en principio múltiples, incluyendo aquellos que superficialmente parecen deberse a una sola persona' (George Joseph Stigler, 1980).

George Joseph Stigler (1980) analizó ejemplos, dentro del análisis económico, concluyendo que "las teorías de la renta, la competencia monopólica, la de los costos comparativos y la refutación de la teoría del fondo de salarios, son ejemplos de verdaderas creaciones múltiples; la teoría de la productividad marginal es mucho menos múltiple; y en el caso de la de la utilidad la multiplicidad es más dudosa". Por lo cual sostiene que "la tesis fundamental de Merton aparece reafirmada, aunque rigurosamente los descubrimientos múltiples no son tan frecuentes".

Stephen Mack Stigler (1980), hijo de George Joseph, complementó el análisis realizado por su padre, formulando la "ley de eponimia de Stigler", según la cual "ningún descubrimiento científico está asociado con el apellido de su descubridor original". Ley que también se aplica a Stigler, precisamente porque esto había sido descubierto por... Merton (1973). Este último distingue tres niveles, en el orden jerárquico de la práctica de la eponimia: los referidos a una época entera, a la paternidad de una ciencia o a una ley, teoría, teorema, hipótesis, instrumento, constante o distribución, específicos.

Cuando le tocó, Albert Otto Hirschman lo tomó con humor: "El índice de concentración del comercio exterior, que inventé en 1945, la literatura económica lo asocia con Corrado Gini, que no lo inventó, y con Orris Clemens Herfindahl (1950), que lo reinventó. Qué le vamos a hacer, vivimos en un mundo cruel" (Hirschman, 1964).

\section{BIBLIOGRAFÍA}

Cairncross, A. K., \& Watts, N. (1989). The economic section, 1939-1961. A study in economic advising. Londres: Routledge.

Calvo, G. A. (1998). Capital flows and capital-market crises: the simple economics of sudden stops, Journal of applied economics, 1(1), 35-54. doi:10.1080 / 15140326.1998.12040516 
Calvo, G. A., Leiderman, L., \& Reinhart, C. (1993). Capital inflows and the real exchange rate appreciation in Latin America: the role of external factors, IMF Staff papers, 40(1), 108-151. doi: https://doi.org/10.2307/3867379

Dornbusch, R. W. (1980). Open economy macroeconomics. New York: Basic Books.

Frenkel, J. A., \& Johnson, H. G. (Eds.) (1976). The monetary approach to the balance of payments. London: Allen.

Friedman, M. (1987). Quantity theory of money. En J. Eatwell, M. Milgate, \& P. Newman (Eds.). The New Palgrave: A Dictionary of Economics, (vol. 4, 3-20). London: Macmillan.

Herfindahl, O. C. (1950). Concentration in the U. S. steel industry (Tesis doctoral). New York: Columbia University.

Hirschman, A. O. (1945). National power and the structure of foreign trade. Berkeley and Los Angeles: University of California Press.

Hirschman, A. O. (1964). The paternity of an index. The American Economic Review, 54(5), 761-762.

Howson, S. (2011). Lionel Robbins (Historical Perspectives on Modern Economics). Cambridge: Cambridge University Press. doi: 10.1017/CBO9781139003544

Merton, R. K. (1973). The sociology of science. Chicago and London: University of Chicago Press.

Mundell, R. A. (1968). International Economics. New York: Macmillan.

Olivera, J. H. G. (1967). Money prices and fiscal lags: a note on the dynamics of inflation. Banca Nazionale del Lavoro Quarterly Review, 20(82), 258-267.

Pablo, J. C. de (2006). Entrevista a Guillermo Antonio Roberto Calvo. Revista de Economía y Estadística, 44(2), 7-25. Recuperado de https://revistas.unc. edu.ar/index.php/REyE/article/view/3828

Pablo, J. C. de (2018). Diez economistas argentinos: origen, trayectoria y obra. Rosario: Grupo Unión.

Pinedo, F. (1968). Trabajoso resurgimiento argentino. Buenos Aires: Fundación del Banco de Galicia.

Popescu, O. (1983). Aspectos analíticos en la doctrina del justo precio en Juan de Matienzo (1520-1579). Económica, 29(1), 83-133. Recuperado de https:// revistas.unlp.edu.ar/Economica/article/view/8021

Popescu, O. (1984). Orígenes hispanoamericanos de la teoría cuantitativa. (Serie Ensayos y conferencias, 3). Buenos Aires: Pontificia Universidad Católica Argentina.

Popescu, O. (1986). El pensamiento económico en la Escolástica Hispanoamericana. Económica, 32(2), 227-260. Recuperado de https://revistas.unlp.edu. ar/Economica/article/view/5565 
Popescu, O. (1986a). Estudios en la historia del pensamiento económico latinoamericano. Bogotá: Plaza \& Janes.

Samuelson, M. C. (1939). The australian case for protection reexamined. The Quarterly journal of economics, 54(1), 143-149.

Stigler, G. J. (1980). Merton on multiples, denied and affirmed. Transactions of the New York Academy of Sciences, 39(1). doi: https://doi. org/10.1111/j.2164-0947.1980.tb02774.x

Stigler, G. J. (1982). The economist as a preacher. Chicago: University of Chicago Press.

Stigler, S. M. (1980). Stigler's law of eponymy. Transactions of the New York Academy of Science, 39(1). 147-157. doi: https://doi. org/10.1111/j.2164-0947.1980.tb02775.x

Stolper, W. F., \& Samuelson, P. A. (1941). Protection and real wages. Review of Economic Studies 9(1), 58-73.

Tanzi, V. (1977). Inflación, rezagos en la recaudación y el valor real de los ingresos tributarios. Ensayos económicos, Junio (2), 5-24.

(C) 2022 por los autores; licencia no exclusiva otorgada a la revista Estudios económicos. Este artículo es de acceso abierto y distribuido bajo los términos y condiciones de una licencia Atribución-No Comercial 4.0 Internacional (CC BY-NC 4.0) de Creative Commons. Para ver una copia de esta licencia, visite http://creativecommons.org/licenses/by-nc/4.0 
